\title{
Influência da adubação com dejeto suíno e adubo mineral adicionada de inibidor de nitrificação sobre a produtividade e a nutrição do milho
}

\author{
Influence of fertilization with swine manure and mineral fertilizer added by nitrification inhibitor on corn yield \\ and nutrition
}

\section{Carmem Thayse de Freitas Alves ${ }^{1}$, Paulo Cezar Cassol ${ }^{2 *}$, Wagner Sacomori ${ }^{2}$, Luciano Colpo Gatiboni ${ }^{2}$, Paulo Roberto Ernani ${ }^{2}$, Celso Aita ${ }^{3}$, Jonas Panisson ${ }^{2}$ e Ana Karolina Teixeira Ferreira ${ }^{2}$}

\author{
Recebido em 16/09/2015 / Aceito em 05/09/2016
}

\section{RESUMO}

A suinocultura se destaca entre as atividades econômicas de Santa Catarina, tanto pelo número de animais criados, quanto pelo grande volume de dejeto líquido de suíno (DLS) que gera. O DLS possui valor fertilizante, porém seu uso excessivo ou inadequado pode poluir as águas superficiais e subterrâneas além de contribuir na emissão de gases do efeito estufa. Para avaliar a incorporação no solo e a adição de inibidor de nitrificação, como formas de aumentar a eficiência do DLS e de fertilizante mineral (NPK) como fontes de nitrogênio $(\mathrm{N})$ e de outros nutrientes à cultura do milho, um experimento foi conduzido na região do Planalto de Santa Catarina. Os tratamentos compreenderam os fertilizantes DLS e NPK, a presença e ausência da dicianodiamida (DCD), testemunha e as formas de aplicação superficial (Sup) e incorporada (Inc) e foram organizados no delineamento blocos casualizados, com parcelas subdivididas e quatro repetições. A incorporação dos fertilizantes aumentou o teor de $\mathrm{N}$ nas folhas, os rendimentos de fitomassa da parte aérea e de grãos e o acúmulo de $\mathrm{N}$ e $\mathrm{K}$ na fitomassa e de P nos grãos de milho. A DCD em geral não afetou o rendimento de grãos, exceto na aplicação superficial do DLS onde a sua presença aumentou o rendimento comparado à sua ausência. Os fertilizantes DLS e NPK mineral possuem eficiência semelhante que aumenta com a incorporação no solo comparada à aplicação em superfície.

PALAVRAS-CHAVE: esterco, adubo orgânico, dicianodiamida, Zea mays.

\section{ABSTRACT}

Swine production in Santa Catarina is remarkable because of both the large number of animals as well as the high volume of swine slurry (DLS) generated. The DLS has fertilizer value, but its excessive or improper use can pollute surface and groundwater as well as contribute to the emission of greenhouse gases. An experiment was carried out in the Santa Catarina plateau to evaluate the incorporation into the soil and the addition of nitrification inhibitor as ways to increase the efficiency of DLS and mineral fertilizer (NPK) as sources of nitrogen (N) and other nutrients for corn. The treatments were the DLS and NPK fertilizers, the presence and absence of dicyandiamide (DCD), a control and the surface (Sup) or incorporated (Inc) applications and were arranged in a randomized block design with split plots and four replicates. The incorporation of fertilizer increased the $\mathrm{N}$ content in leaves, shoot dry matter and grain yields and the accumulation of $\mathrm{N}$ and $\mathrm{K}$ in the dry matter and $\mathrm{P}$ in corn grain. The DCD in general did not affect grain yield, except in superficial application of the DLS where their presence increased the yield compared to its absence. The DLS and mineral NPK fertilizers have similar efficiency that increases with incorporation into the soil compared to the surface application.

KEYWORDS: manure, organic fertilizer, dicyandiamide, Zea mays.

\footnotetext{
${ }^{1}$ Empresa de Pesquisa Agropecuária e Extensão Rural de Santa Catarina, Lages, SC, Brasil.

${ }^{2}$ Universidade do Estado de Santa Catarina, Lages, SC, Brasil.

${ }^{3}$ Universidade Federal de Santa Maria, Santa Maria, RS, Brasil.

*Autor para correspondência <paulo.cassol@udesc.br>
} 


\section{INTRODUÇÃO}

A suinocultura, com sua cadeia produtiva, consolidou-se como uma das principais atividades econômicas do estado de Santa Catarina e vem apresentando crescimento continuado (ABIPECS 2012). Com isso, aumentou o volume de dejeto líquido de suíno (DLS), resíduo que se caracteriza pela mistura de fezes, urina, restos de alimentos e água derivada dos bebedouros e da higienização das baias. Estima-se que cada suíno em fase de terminação gera cerca de 4,5 litros de dejeto diariamente (FATMA 2014).

O uso do dejeto como fonte de nutrientes pode contribuir para diminuir a pressão sobre as reservas minerais de nutrientes que são finitas e altamente influenciadas por fatores que determinam as oscilações de preços no mercado. Estima-se, que essas reservas sejam capazes de suprir os patamares produtivos por 55, 93 e 235 anos, respectivamente, para o N, P e K produzidos mundialmente (FIXEN 2009). Contudo, os nutrientes contidos no DLS se encontram diluídos, o que inviabiliza seu transporte a longas distâncias. Com isso, o manejo empregado pela maioria dos produtores são aplicações sucessivas, normalmente em áreas próximas das unidades produtoras.

O plantio direto é considerado um sistema conservacionista e praticado pela maioria dos produtores. Quando bem conduzido preconiza a manutenção de cobertura vegetal no solo, não há revolvimento e as práticas culturais são em geral feitas na superfície, inclusive a fertilização. Nesse sistema, em geral aumentam as concentrações de nutrientes, como o $\mathrm{P}$, nas camadas mais superficiais, o que favorece que sejam transportados por escoamento superficial e venham a causar eutrofização das águas superficiais (BERTOL et al. 2004). Segundo esses autores, as maiores perdas de nutrientes por escoamento superficial ocorrem nas aplicações superficiais de DLS em sistema de plantio direto. A aplicação superficial do DLS também favorece as perdas de nitrogênio $(\mathrm{N})$, por volatilização, sabendo-se que aproximadamente $80 \%$ do $\mathrm{N}$ presente nos dejetos se encontra na forma amoniacal (SCHIRMANN et al. 2013), que é prontamente disponível para as plantas.

As perdas de $\mathrm{N}$ e de outros nutrientes são acentuadas quando o DLS é aplicado superficialmente (NICOLOSO et al. 2013, SCHIRMANN et al. 2013). Entretanto, a incorporação do DLS no solo pode reduzir em até $90 \%$ as perdas de $\mathrm{N}$ por volatilização
(DAMASCENO 2010, SCHIRMANN et al. 2013), além de favorecer o aproveitamento dos demais nutrientes contidos, principalmente do fósforo.

As perdas de $\mathrm{N}$ da adubação também podem ser reduzidas pelo uso de inibidores de nitrificação, como a dicianodiamida (DCD), que tem efeito bateriostático sobre o gênero Nitrossomonas e retarda o processo de nitrificação (DI \& CAMERON 2004). Com isso, a DCD pode reduzir em até $78 \%$ a lixiviação de $\mathrm{NO}_{3}^{-}$no perfil do solo (VALLEJO et al. 2005), podendo aumentar o teor de $\mathrm{N}$ na fitomassa das plantas (NICOLOSO et al. 2013) e ainda, reduzir as emissões de $\mathrm{N}_{2} \mathrm{O}$ e $\mathrm{N}_{2}$, para atmosfera em até 80\% (SCHIRMANN et al. 2013). Assim, a adição da DCD ao DLS pode melhorar a eficiência desse fertilizante quando aplicado no solo, aumentando em cerca de $39 \%$ o acúmulo de $\mathrm{N}$ pela cultura do milho (SCHIRMANN et al. 2013).

Nesse contexto, o objetivo deste trabalho foi avaliar o desempenho do dejeto líquido de suíno e do fertilizante NPK em aplicações na superfície ou incorporados no solo e adicionados de inibidor de nitrificação na cultura do milho em sistema de plantio direto.

\section{MATERIAL E MÉTODOS}

O trabalho foi conduzido a campo nas safras de 2011/12 e 2012/13 em áreas de Nitossolo Háplico e Cambissolo Húmico, respectivamente, cujas características são apresentadas na Tabela 1. As duas áreas se situam no município de Lages, SC, em altitudes entre de 850 e $900 \mathrm{~m}$ acima do nível do mar, a primeira na localidade de Santa Terezinha do Salto, a 2749'09' de Latitude Sul e 50 $18^{\prime} 10^{\prime \prime}$ de Longitude Oeste e a segunda nas dependências do Centro de Ciências Agroveterinárias da Universidade do Estado de Santa Catarina, a $27^{\circ} 49^{\prime} 00^{\prime}$ de Latitude Sul e $50^{\circ} 35^{\prime} 50^{\prime \prime}$ de Longitude Oeste. O clima de ambas as áreas é caracterizado como mesotérmico úmido, com verão ameno ( $\mathrm{Cfb}$ segundo a classificação de Köppen). As chuvas são distribuídas durante o ano e as médias anuais de precipitação e temperatura são de $1.550 \mathrm{~mm}$ e $15,6^{\circ} \mathrm{C}$, respectivamente.

Anteriormente a implantação do experimento, a área de Nitossolo vinha sendo utilizada com cultivo de milho no verão e pastagem de gramínea submetida a pastoreio direto no inverno, sendo anualmente fertilizada e conduzida sob plantio direto há cerca de oito anos. A área de Cambissolo foi anteriormente 
Tabela 1 - Valores de pH, SMP, V\%, H+Al, Ca, Mg, P, K, Argila e MO da camada de 0-20 cm de profundidade do Nitossolo Háplico $(\mathrm{NH})$ e Cambissolo Húmico $(\mathrm{CH})$ e características do dejeto líquido de suínos (DLS) oriundo de central de produção de leitões (Safra 2011/12) e fêmeas em fase de recria (Safra 2012/13).

Table 1 - Soil atributes pH, SMP, V\%, H+Al, Ca, Mg, P, K, Clay and MO of 0-20 cm layer of Haplic Nitosol (NH) and Inceptiso $(\mathrm{CH})$, and characteristics of swine manure, originating from pig lets production plant (2011/12 harvest) and females growing phase (2012/13 harvest).

\begin{tabular}{|c|c|c|c|c|c|c|c|c|c|c|}
\hline Solo & $\mathrm{pH}$ & SMP & V\% & $\mathrm{H}+\mathrm{Al}$ & $\mathrm{Ca}$ & $\mathrm{Mg}$ & $\mathrm{P}$ & $\mathrm{K}$ & Argila & MO \\
\hline & & & & \multicolumn{3}{|c|}{-------cmol $\mathrm{kg}^{-1}-------$} & \multicolumn{2}{|c|}{$--\mathrm{mg} \mathrm{dm}{ }^{-3}--$} & \multicolumn{2}{|c|}{-----\%------ } \\
\hline $\mathrm{NH}$ & 4,9 & 5,3 & 50 & 5,5 & 5,9 & 3,2 & 17,9 & 206 & 65 & 3,4 \\
\hline $\mathrm{CH}$ & 5,2 & 5,9 & 61 & 5,1 & 5,6 & 1,9 & 3,1 & 92 & 30 & 4,1 \\
\hline \multicolumn{2}{|c|}{ Safra } & \multicolumn{2}{|c|}{ Massa seca } & \multicolumn{2}{|c|}{$\mathrm{N}$ total } & \multicolumn{2}{|c|}{$\mathrm{N}^{-\mathrm{NH}_{4}}{ }^{+}$} & $\mathrm{P}$ & \multicolumn{2}{|c|}{ K } \\
\hline & & \multicolumn{2}{|c|}{$\%$} & \multicolumn{7}{|c|}{ 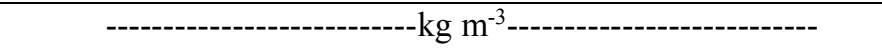 } \\
\hline 2011/1 & & \multicolumn{2}{|c|}{5,5} & \multicolumn{2}{|c|}{3,0} & \multicolumn{2}{|c|}{1,8} & 3,5 & \multicolumn{2}{|c|}{1,4} \\
\hline 2012/1 & & \multicolumn{2}{|c|}{3,8} & \multicolumn{2}{|c|}{3,9} & \multicolumn{2}{|c|}{2,5} & 2,9 & \multicolumn{2}{|c|}{1,3} \\
\hline
\end{tabular}

utilizada como pastagem nativa e seis meses antes da implantação do experimento recebeu calagem com dose equivalente a $8,0 \mathrm{Mg} \mathrm{ha}^{-1}$ de calcário dolomítico incorporado na camada $0-20 \mathrm{~cm}$ e foi cultivada com aveia (Avena strigosa). Essa cultura foi dessecada com glifosato no estágio de florescimento e manejada com rolo faca, mantendo-se a palhada sobre o solo para a aplicação dos tratamentos e implantação da cultura do milho em sistema plantio direto.

Os tratamentos compreenderam um fatorial $2 \times 5$, composto por dois modos de aplicação: em superfície e incorporado no solo e cinco tipos de fertilização: testemunha, sem fertilizantes (TEST), fertilizante mineral (NPK), NPK + dicianodiamida (DCD), dejeto líquido de suíno (DLS) e DLS + DCD. Os tratamentos foram arranjados no delineamento em blocos ao acaso com parcelas subdivididas e quatro repetições. Nas parcelas principais foram alocados os modos de aplicação e nas subparcelas os tipos de fertilizações. As dimensões das parcelas principais foram de $7 \mathrm{~m} \times 25 \mathrm{~m}\left(175 \mathrm{~m}^{2}\right)$ e $8 \mathrm{~m} \times 21 \mathrm{~m}$ $\left(168 \mathrm{~m}^{2}\right)$, nas safras 2011/12 e 2012/13, respectivamente. Já, as subparcelas tiveram as dimensões de 7,0 m x 5,0 m $\left(35 \mathrm{~m}^{2}\right)$ e $8,0 \mathrm{~m} \times 4,2$ $\mathrm{m}\left(33,6 \mathrm{~m}^{2}\right)$, com áreas úteis de $24 \mathrm{~m}^{2}$ e $22,4 \mathrm{~m}^{2}$, nas dimensões de $6,0 \mathrm{~m} \mathrm{x} \mathrm{4,0} \mathrm{m}$ e 7,0 $\mathrm{m}$ x 3,2 m, na primeira e segunda safras, respectivamente.

As doses de fertilizantes foram definidas para o rendimento de grãos de milho de $8,0 \mathrm{Mg}$ $\mathrm{ha}^{-1}$, considerando a fertilidade dos solos onde o experimento foi conduzido, conforme indicado por CQFS-RS/SC (2004). Em ambas as safras, as doses do
NPK corresponderam a 130, 185 e $70 \mathrm{~kg} \mathrm{ha}^{-1} \mathrm{de} \mathrm{N}, \mathrm{P}_{2} \mathrm{O}_{5}$ e $\mathrm{K}_{2} \mathrm{O}$, aplicados usando as fontes ureia, superfosfato triplo e cloreto de potássio, respectivamente, e a dose de DLS foi $40 \mathrm{~m}^{3} \mathrm{ha}^{-1}$, definida para também fornecer $130 \mathrm{Kg} \mathrm{ha}^{-1}$ de $\mathrm{N}$, considerando o índice de eficiência de 0,8 .

A DCD utilizado foi o produto comercial Agrotain Plus ${ }^{\circledR}$ empó, contendo $81 \%$ dedicianodiamida que é formulado juntamente com o inibidor da enzima urease tiofosfato de $\mathrm{N}$-n-butiltriamida $\left(\mathrm{NBPT}^{\circledR}\right)$. A DCD foi misturado aos fertilizantes no momento da aplicação no campo e aplicado em dose equivalente a $10 \mathrm{~kg} \mathrm{ha}^{-1}$.

O DLS utilizado na safra 2011/12 foi obtido de uma granja de produção de leitões, misturandose $50 \%$ de dejeto de um biodigestor e $50 \%$ de uma lagoa que recebe o efluente proveniente do mesmo biodigestor. Na safra de 2012/13, o DLS foi retirado da esterqueira de uma criação suína na fase de recria. A composição dos dejetos empregados está registrada na Tabela 1 e foi determinada conforme metodologia descrita por TEDESCO et al. (1995).

A incorporação do DLS no solo foi realizada com um distribuidor e injetor de dejetos líquidos, desenvolvido pela empresa MEPEL, composto de um tanque de aço para 4.000 litros, bomba de pressurização acionada pela tomada de potência do trator e um conjunto de linhas de injeção. Esse conjunto é fixado na parte posterior do chassi do equipamento e tem acionamento hidráulico pelo trator. As linhas de injeção são espaçadas em $35 \mathrm{~cm}$ compostas por um disco de corte frontal e um facão 
sulcador, em cuja face posterior se encontra a saída do jato do dejeto. Assim, o DLS foi incorporado no sulco feito pelo equipamento, na profundidade de aproximadamente $8 \mathrm{~cm}$, com 10 a $12 \mathrm{~cm}$ de faixa de solo mobilizado na superfície do sulco. Na primeira safra, a aplicação do DLS na superfície do solo foi realizada manualmente, com auxílio de regadores de 10 litros, enquanto na segunda safra essa aplicação foi realizada com o próprio equipamento distribuidor, porém com as linhas de injeção suspendidas. Os fertilizantes NPK foram aplicados manualmente, sendo a lanço quando em superfície e distribuído dentro do sulco aberto pelo equipamento, sem injeção do DLS, quando incorporado.

$\mathrm{Na}$ safra de 2011/12, a aplicação dos tratamentos e semeadura do milho (Zea mays) foram realizados em 11/11/2011 e a colheita, em $11 / 05 / 2012$. Na safra 2012/13 os tratamentos foram aplicados em 27/11/2012, a semeadura foi realizada em 06/12/2012 e a colheita em 05/06/2013. A precipitação média mensal durante os períodos de condução do experimento encontra-se na Figura 1 (EPAGRI/CIRAM 2013). Cultivou-se milho do cultivar Pioneer ${ }^{\circledR}$ 30F53, caracterizado como híbrido simples de ciclo precoce que necessita de soma térmica de 3112 graus dia (GD) até a maturação fisiológica. $\mathrm{O}$ cultivo foi realizado em sistema plantio direto, com espaçamento de $0,7 \mathrm{~m}$ entre as linhas de semeadura, atingindo população de plantas estimada em 76.000 ha $^{-1}$ e 86.000 ha $^{-1}$, na primeira e segunda safras, respectivamente.

As plantas espontâneas foram controladas com aplicação de herbicidas, em pré-emergência, juntamente com a dessecação da aveia e em pósemergência, aproximadamente 20 dias após a germinação do milho.

A produção de fitomassa da primeira e segunda safras foi estimada em amostras de 5 e 8 plantas, respectivamente, colhidas aleatoriamente dentro da área útil das subparcelas, mediante corte rente ao solo quando a cultura atingiu a maturação fisiológica. Estas plantas tiveram as espigas sem palhas (grãos e sabugo) retiradas e foram mantidas em estufa a $65^{\circ} \mathrm{C}$ até atingirem peso constante para determinação da massa seca e moagem. As plantas foram moídas em duas etapas, sendo a primeira em triturador de forragem e a segunda feita em amostras do material triturado retiradas por quarteações sucessivas, em moinho de facas, até diâmetro menor que $2 \mathrm{~mm}$, para determinação dos teores de N, P e K, conforme metodologia descrita por TEDESCO et al. (1995).

A colheita de grãos foi realizada quando as plantas atingiram a maturação plena, com coleta manual das espigas de cada subparcela, que foram trilhadas mecanicamente, estimando-se o rendimento de grãos com umidade corrigida para o padrão de $13 \%$.

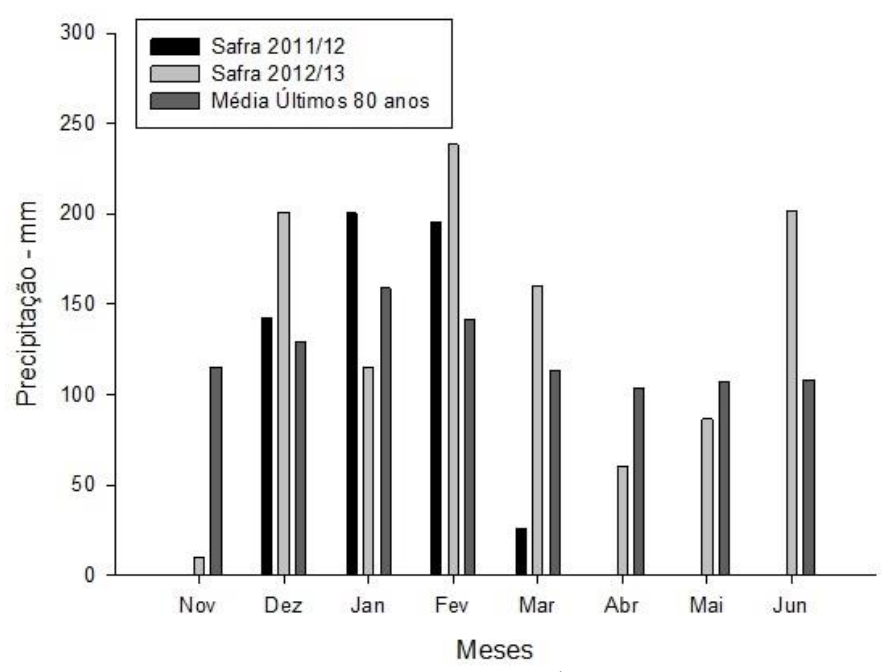

Fonte: EPAGRI/CIRAM 2013.

Figura 1 - Precipitação média mensal (mm), ocorrida durante a condução do experimento, nas safras 2011/12 (Safra 2011/12) e 2012/13 (Safra 2012/13), e precipitação média para a região dos últimos 80 anos de 1925 e 2005.

Figure 1 - Average monthly precipitation (mm), which occurred during the experiment, per season, 2011/12 (2011/12 harvest) and 2012/13 (2012/13 harvest), and average rainfall for the region in 80 years 1925 and 2005. 
Amostras com aproximadamente $200 \mathrm{~g}$ de grãos foram coletadas e secas em estufa a $65^{\circ} \mathrm{C}$, para determinação do teor de umidade e dos teores de N, P e K, após terem sido moídas em moinho de facas até diâmetro menor do que $2 \mathrm{~mm}$. $\mathrm{O}$ acúmulo de nutrientes na fitomassa e nos grãos do milho foi calculado a partir dos valores da respectiva massa seca e respectivos teores de N, P e K contidos.

Os resultados foram submetidos à análise de variância pelo teste $\mathrm{F}$, considerando as safras como sub-subparcelas, com a comparação entre médias pelo teste Tukey a 5\% de significância.

\section{RESULTADOS E DISCUSSÃO}

Os resultados das variáveis determinadas nas duas safras seguiram as mesmas tendências, pois não houve interação entre safra e tratamentos. Com isso, são apresentados e discutidos os valores médios das duas safras avaliadas. O rendimento de fitomassa da parte aérea do milho variou de 5,51 até 7,60 $\mathrm{Mg} \mathrm{ha}^{-1}$ (Figura 2A). Esse valor maior foi aproximadamente $40 \%$ menor em relação ao observado por SCHIRMANN et al. (2013) em cultivo de milho fertilizados com DLS aplicado em superfície. Entretanto, além do efeito da diferença do clima entre os locais dos estudos, essa diferença se explica porque nesse atual estudo, a cultura não recebeu irrigação, que foi fornecida no experimento daqueles autores, onde se demonstrou o alto potencial de resposta da cultura à fertilização com DLS em área sem déficit hídrico.

Aprodução de fitomassa também evidenciou que tanto o DLS quanto o fertilizante mineral forneceram nutrientes em quantidade suficiente, tanto na ausência como na presença do inibidor DCD (Figura 2A), pois a fertilização aumentou o rendimento em relação à testemunha, independentemente da fonte ter sido orgânica (DLS) ou mineral (NPK) ou da presença da DCD.

A adição de inibidor de nitrificação também aumentou a produção de fitomassa da parte aérea do milho (Figura 2A) quando foi feita aplicação superficial de $\mathrm{NPK}+\mathrm{DCD}$, em relação à sua incorporação ao solo. Isso também indica o aumento da eficiência do fertilizante, pela adição do inibidor de nitrificação, o que se atribui ao aumento da disponibilidade de $\mathrm{N}$, durante o período de tempo de absorção pela cultura. Entretanto, em geral não houve diferença significativa da adição de DCD entre os tratamentos que receberam o inibidor e aqueles onde ele não foi utilizado.
$\mathrm{O}$ rendimento de grãos na cultura do milho variou de 4,4 até 8,3 $\mathrm{Mg} \mathrm{ha}^{-1}$ (Figura 2B). Na região do estudo, o potencial do rendimento de grãos do milho em experimento a campo contendo irrigação, foi estimado em até $16 \mathrm{Mg} \mathrm{ha}^{-1}$ (ARGENTA et al. 2003). Entretanto, nas duas safras em que o experimento foi conduzido, a disponibilidade hídrica foi determinada pela capacidade de armazenamento de água do solo e ocorrência de precipitações (Figura 1), já que em nenhuma das duas áreas houve irrigação. Outro fator interferente foi relacionado ao acúmulo térmico, onde o déficit observado no local do experimento, em relação ao recomendado para o melhor desempenho da cultivar certamente também contribuiu para limitar a produção de fitomassa da parte aérea. Rendimentos que variaram de 8,1 até $10 \mathrm{Mg} \mathrm{ha}^{-1} \mathrm{em}^{-}$campos irrigados e fertilizados com DLS aplicado em superfície foram relatados por SCHIRMANN et al. (2013).

A semelhança de produtividade observada no experimento, evidencia que o DLS e o fertilizante NPK forneceram nutrientes em quantidade equivalente, tanto na ausência como na presença do inibidor DCD (Figura 2B), pois a fertilização aumentou o rendimento em relação a testemunha não fertilizada, independentemente da fonte ter sido orgânica (DLS) ou mineral (NPK) ou da presença do inibidor de nitrificação (DCD).

Os tratamentos que tiveram incorporação dos fertilizantes ao solo foram mais produtivos que os que receberam a fertilização em superfície (Figuras $2 \mathrm{~A}$ e $2 \mathrm{~B}$ ), inclusive na testemunha indicando que seu efeito pode em parte ser devido à mobilização do solo. Desta forma, a incorporação favoreceu o rendimento de grãos do milho, que, teve incremento médio de $13 \%$ quando os fertilizantes foram incorporados em relação a aplicação superficial. Isso indica que a incorporação pode ser vantajosa, ou justificável sob o ponto de vista da eficiência dos fertilizantes no solo. A incorporação também aumentou a eficiência agronômica do DLS e como reflexo a produtividade do milho em trabalho semelhante desenvolvido por NICOLOSO et al. (2013).

As fontes de fertilizantes orgânico e mineral, não diferiram entre si no rendimento de grãos, o que demonstra que o DLS também supriu as exigências nutricionais de N, P e K da cultura do milho, para o nível de produtividade obtido.

Nos tratamentos em que o DLS foi aplicado juntamente com o inibidor de nitrificação, DCD, não houve diferença significativa entre incorporação 
(A)

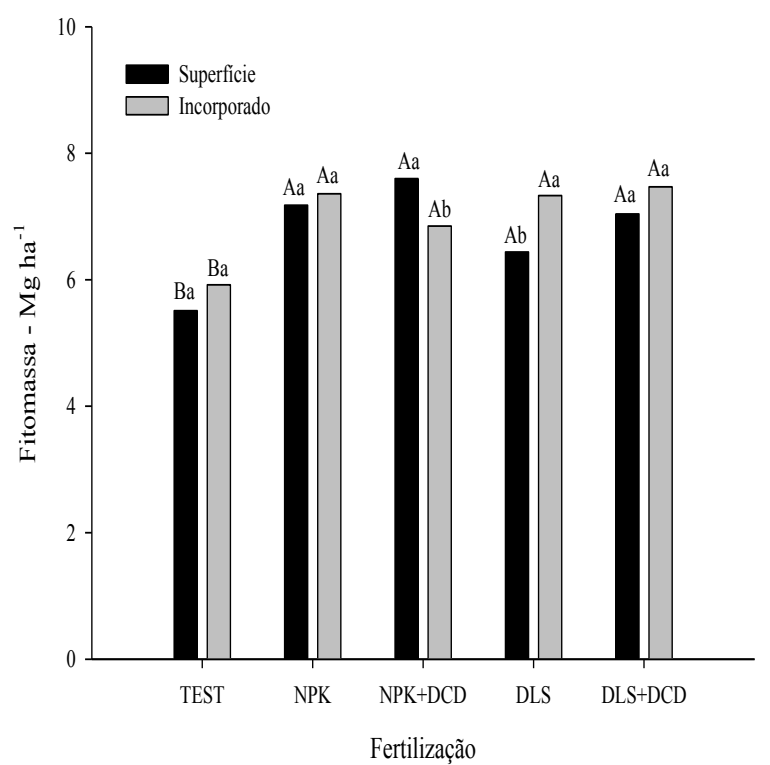

(B)

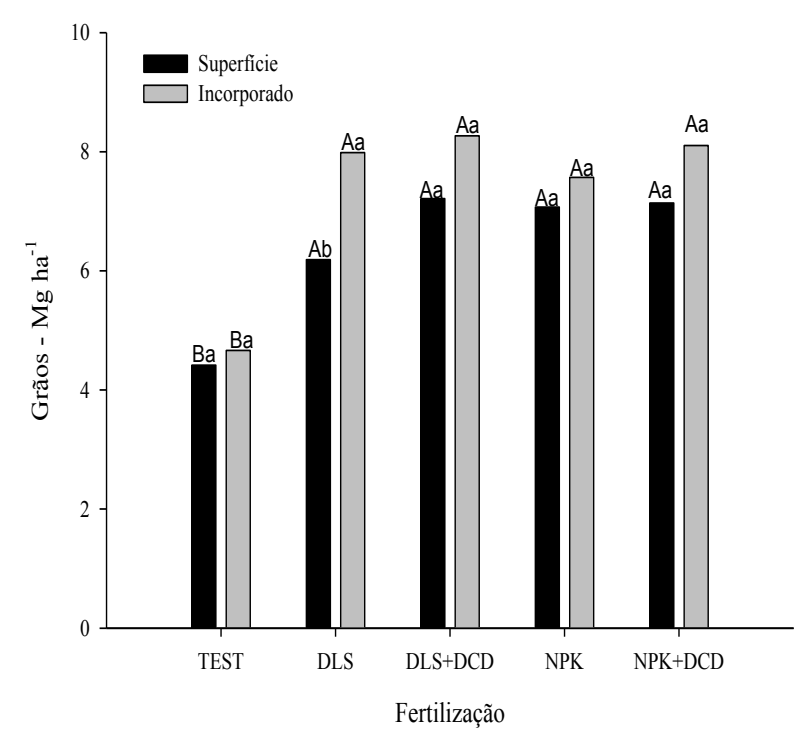

Obs.: Colunas com letras distintas, maiúsculas entre as fertilizações e minúsculas entre superfície e incorporado diferem entre si pelo teste de Tukey $(\mathrm{p} \leq 0,05)$.

Figura 2 - Rendimentos $\left(\mathrm{Mg} \mathrm{ha}^{-1}\right)$ de fitomassa da parte aérea (A) e de grãos (B) de milho sem fertilização (TEST) e sob fertilização com dejeto líquido de suíno (DLS) e fertilizante mineral (NPK), acrescidos ou não de dicianodiamida (DCD) e aplicados em superfície ou incorporados no solo.

Figure 2 - Corn yield of shoot biomass (A) and grain (B), without fertilization (TEST) and fertilized with swine slurry (DLS) and mineral fertilizer (NPK) with or without addition of dicyanodiamide (DCD), applied on the surface and incorporated into the soil

ou aplicação superficial ao solo, evidenciando desta forma que a DCD pode ter contribuído na manutenção do $\mathrm{N}$ disponível fornecido pelo DLS aplicado em superfície. Esse efeito se deve basicamente a capacidade do inibidor de retardar o processo de nitrificação, conforme observado por DAMASCENO (2010) e com isso aumentar a quantidade de $\mathrm{N}$ amoniacal retido no solo, aumentando o período de seu fornecimento às plantas. Entretanto, nas condições do experimento não houve benefício significativo deste aditivo no rendimento de grãos, ou seja, a DCD não afetou o rendimento de grãos nos tratamentos onde ele foi utilizado em relação aos que não esteve presente.

A quantidade de $\mathrm{N}$ acumulada na fitomassa de milho (Tabela 2) variou entre 32 até $64 \mathrm{~kg} \mathrm{ha}^{-1} \mathrm{e}$ nos grãos, de 53 até $111 \mathrm{~kg} \mathrm{ha}^{-1}$, valores equivalentes com os observados no trabalho de SCHIRMANN et al. (2013), que encontraram quantidades médias de $\mathrm{N}$ acumulado de $59,2 \mathrm{~kg} \mathrm{ha}^{-1}$ nos grãos e $55 \mathrm{~kg} \mathrm{ha}^{-1}$ na fitomassa produzida. $\mathrm{O} \mathrm{N}$ acumulado, tanto na fitomassa, quanto nos grãos foi maior nos tratamentos com fertilização em relação àqueles não fertilizados. Tal comportamento também foi observado por BERENGUER et al. (2008), o que se deve ao rápido crescimento da cultura, que por isso respondeu favoravelmente as fertilizações realizadas.

Houve evidência de maior rendimento e acúmulo de $\mathrm{N}$ quando os fertilizantes foram incorporados ao solo (Tabela 2), que demonstra que em média, a incorporação pode aumentar a eficiência do fertilizante em relação à aplicação superficial. A ausência de diferença entre os fertilizantes orgânicos e minerais, demonstra que o DLS é tão eficiente quanto o fertilizante mineral para o fornecimento de $\mathrm{N}$ ao acúmulo na fitomassa da parte aérea e nos grãos para a cultura do milho. A DCD também não influenciou o acúmulo de $\mathrm{N}$ no milho, na fitomassa da parte aérea e grãos, resultado este consonante com o verificado no trabalho de SCHIRMANN et al. (2013) que conduziu experimentos com DLS manejado com fertilizações superficiais e DCD.

$\mathrm{O}$ acúmulo de $\mathrm{P}$ na fitomassa da parte aérea (Tabela 3), não apresentou na média dos tratamentos, diferença quando os fertilizantes foram aplicados superficialmente em relação a sua incorporação ao solo. Porém, no P acumulado pelos grãos a média dos tratamentos com os fertilizantes incorporados ao solo foi superior em relação à aplicação superficial. 
Tabela 2 - Acúmulo de nitrogênio (N) na fitomassa da parte aérea e nos grãos do milho fertilizados com adubo mineral (NPK) ou dejeto líquido de suíno (DLS) incorporado (Inc) ou aplicado superficialmente (Sup) ao solo e acrescido (+DCD) ou não de dicianodiamida, e ainda testemunha (TEST), não fertilizada.

Table 2 - Accumulation of nitrogen $(N)$ in the shoot biomass and in the grains of corn fertilized with mineral fertilizer (NPK) or swine manure (DLS) incorporated (Inc) or applied superficially (Sup) in the soil and dicyandiamide added (+DCD) or not, and a control (TEST), not fertilized.

\begin{tabular}{lcccccc}
\hline & \multicolumn{5}{c}{ Fertilizantes } \\
Modo & NPK & NPK+DCD & DLS & DLS+DCD & TEST & Média \\
\cline { 2 - 5 } Inc & $63 \mathrm{a}$ & $62 \mathrm{a}$ & $64 \mathrm{a}$ & $63 \mathrm{a}$ & $35 \mathrm{~b}$ & $58 \mathrm{~A}$ \\
Sup & $56 \mathrm{a}$ & $59 \mathrm{a}$ & $50 \mathrm{a}$ & $53 \mathrm{a}$ & $33 \mathrm{~b}$ & $50 \mathrm{~B}$ \\
& & & fitomassa $-\mathrm{kg} \mathrm{ha}^{-1}$ & & \\
Inc & $92 \mathrm{a}$ & $111 \mathrm{a}$ & $108 \mathrm{a}$ & $100 \mathrm{a}$ & $53 \mathrm{~b}$ & $93 \mathrm{~A}$ \\
Sup & $80 \mathrm{a}$ & $81 \mathrm{a}$ & $67 \mathrm{a}$ & $75 \mathrm{a}$ & $56 \mathrm{~b}$ & $72 \mathrm{~B}$ \\
\hline
\end{tabular}

Médias seguidas por letras distintas (minúsculas na horizontal e maiúsculas na vertical) diferem entre si pelo teste de Tukey $(\mathrm{p} \leq 0,05)$.

Tabela 3 - Acúmulo de fósforo $(\mathrm{P})$ e potássio $(\mathrm{K})$ pelos Grãos e pela fitomassa da parte aérea do milho fertilizados com adubo mineral (NPK) ou dejeto de suíno (DLS) incorporado (Inc) ou aplicado superficialmente (Sup) ao solo e acrescido (+DCD) ou não de dicianodiamida, e ainda testemunha (TEST), não fertilizada.

Table 3 - Phosphorus (P) and potassium (K) accumulation by the grains and the weight of shoot of corn, fertilized with mineral fertilizer (NPK) or swine manure (DLS) incorporate (Inc) or applied superficially (Sup) in the soil and dicyandiamide added (+DCD) or not and a control (TEST), not fertilized.

\begin{tabular}{|c|c|c|c|c|c|c|}
\hline \multirow[b]{2}{*}{ Modo } & \multicolumn{6}{|c|}{ Fertilizantes } \\
\hline & NPK & $\mathrm{NPK}+\mathrm{DCD}$ & DLS & $\mathrm{DLS}+\mathrm{DCD}$ & TEST & Média \\
\hline & \multicolumn{6}{|c|}{ Fitomassa } \\
\hline & & & $\mathrm{kg} \mathrm{ha}^{-1}$ & & & \\
\hline Inc & $8,95 a$ & $8,77 \mathrm{ab}$ & $7,47 \mathrm{ab}$ & $8,89 \mathrm{a}$ & $6,44 \mathrm{~b}$ & $8,10 \mathrm{~A}$ \\
\hline \multirow[t]{2}{*}{ Sup } & $7,85 \mathrm{a}$ & $7,35 \mathrm{ab}$ & $8,63 \mathrm{ab}$ & $8,79 a$ & $6,31 b$ & $7,78 \mathrm{~A}$ \\
\hline & & & $\mathrm{K} \mathrm{kg}$ ha & & & \\
\hline Inc & $135 \mathrm{a}$ & $133 a$ & $115 a$ & $108 \mathrm{ab}$ & $100 \mathrm{~b}$ & $118 \mathrm{~A}$ \\
\hline \multirow[t]{3}{*}{ Sup } & $117 \mathrm{a}$ & $100 \mathrm{a}$ & $117 \mathrm{a}$ & $110 \mathrm{ab}$ & $75,1 b$ & 104B \\
\hline & \multicolumn{6}{|c|}{ Grãos } \\
\hline & & & $\mathrm{P} \mathrm{kg}$ ha & & & \\
\hline Inc & $23,5 \mathrm{a}$ & $24,4 \mathrm{a}$ & $26,4 \mathrm{a}$ & $26,3 a$ & $14,6 b$ & $23,0 \mathrm{~A}$ \\
\hline \multirow[t]{2}{*}{ Sup } & $21,4 \mathrm{a}$ & $21,7 \mathrm{a}$ & $19,6 \mathrm{a}$ & $24,0 \mathrm{a}$ & $14,7 b$ & $20,3 \mathrm{~B}$ \\
\hline & & & $-\mathrm{K} \mathrm{kg} \mathrm{ha}$ & & & \\
\hline Inc & $113 a$ & $120 \mathrm{a}$ & $117 \mathrm{a}$ & $122 a$ & $63,2 b$ & $107 \mathrm{~A}$ \\
\hline Sup & $90,5 \mathrm{a}$ & $81,0 \mathrm{a}$ & $73,3 \mathrm{a}$ & $89,3 a$ & $45,7 b$ & $76,0 \mathrm{~B}$ \\
\hline
\end{tabular}


Isso indica que a incorporação foi mais eficiente que a aplicação superficial para as quantidades de P acumulada nos grãos de milho.

$\mathrm{O}$ tratamento que se destacou em resultado significativo para a quantidade de $\mathrm{P}$ acumulada nos grãos foi o DLS incorporado ao solo em relação a sua aplicação superficial. Isso evidencia que a incorporação aumenta a disponibilidade desse nutriente contido no fertilizante, o que se atribui à maior proximidade com as raízes, presença de umidade do solo e proteção contra perdas por erosão propiciada pela incorporação. Não houve diferença entre os teores de $\mathrm{P}$ acumulados na fitomassa da parte aérea e nos grãos entre os tratamentos, e nem quando foi aplicado inibidor de nitrificação em relação aos tratamentos onde ele não foi utilizado.

Nos grãos as quantidades de $\mathrm{K}$ acumuladas variaram de 44 a $120 \mathrm{~kg} \mathrm{ha}^{-1}$, e na fitomassa da parte aérea os valores situaram-se entre 57 a $128 \mathrm{~kg} \mathrm{ha}^{-1}$. Seguindo as tendências de aumento de eficiência quando incorporado, a injeção do fertilizante ao solo proporcionou maiores acúmulos em média, do que quando os fertilizantes foram aplicados superficialmente. Os resultados evidenciaram aumento do acumulo como provável consequência da maior absorção pela planta, quando os fertilizantes foram adicionados ao solo. Ou seja, a fertilização aumentou a disponibilidade dos nutrientes para a cultura do milho em plantio direto. A incorporação ao solo proporcionou ao tratamento NPK+DCD diferenças significativas, tanto no acúmulo de nutrientes pelos grãos, quanto pela fitomassa da parte aérea. Entretanto, nos demais tratamentos, incluindo a testemunha, apesar de todos se apresentarem numericamente superiores, tal superioridade não foi significativa estatisticamente. Os tratamentos que receberam fertilização não diferiram entre si, demonstrando que os solos apresentaram capacidade em fornecer $\mathrm{K}$ para a cultura do milho mesmo quando a dose de fertilizante aplicado é calibrada pelo N, e ainda que a adição de DCD também não influenciou a absorção e acúmulo deste nutriente.

\section{CONCLUSÃO}

A incorporação ao solo aumenta a eficiência, tanto do fertilizante mineral, quanto do orgânico, melhorando o desempenho produtivo de milho em rendimentos de fitomassa da parte aérea e de grãos.

$\mathrm{O}$ teor de $\mathrm{N}$ nas folhas do milho é maior quando os fertilizantes são incorporados em sulco no solo em relação à aplicação superficial e a incorporação dos fertilizantes também possibilita um maior teor e consequente maior acúmulo de $\mathrm{N}$ e $\mathrm{K}$ na fitomassa vegetativa e nos grãos e de $\mathrm{P}$ nesse produto.

$\mathrm{O}$ dejeto líquido de suíno tem eficiência semelhante às fontes minerais na adubação do milho.

A adição de inibidor de nitrificação em geral não influencia no teor de $\mathrm{N}$ na planta, tampouco nas quantidades desse nutriente acumulados pelo milho e também não afeta o rendimento de grãos e fitomassa dessa cultura.

\section{REFERÊNCIAS}

ABIPECS - Associação Brasileira da Indústria Produtora e Acumuladora de Carne Suína. 2012. Disponível em: http:// www.abipecs.org.br/. Acesso em: 22 abr. 2013.

ARGENTA $G$ et al. 2003. Potencial de rendimento do milho em dois ambientes e cinco sistemas de produção. Scientia Agraria 4: 27-34.

BERENGUER $P$ et al. 2008. Fertilization of irrigated maize with pig slurry combined with mineral nitrogen. European Journal Agronomy 28: 635-645.

BERTOL I et al. 2004. Perdas de fósforo e potássio por erosão hídrica em um Inceptisol sob chuva natural. Revista Brasileira de Ciência do Solo 28: 485-494.

CQFS-RS/SC - Comissão de Química e Fertilidade do Solo - RS/SC. 2004. Manual de adubação e de calagem para Estados do Rio Grande do Sul e de Santa Catarina. 10.ed. Porto Alegre: CQFS/SBCS. 400p.

DAMASCENO F. 2010. Injeção de dejetos líquidos de suínos no solo e inibidor de nitrificação como estratégias para reduzir as emissões de amônia e óxido nitroso. Dissertação (Programa de Pós-Graduação em Ciências em Ciência do Solo). Santa Maria: UFSM. 121f.

DI HJ \& CAMERON KC. 2004. Effects of temperature and application rate of a nitrification inhibitor, dicyanodiamide (DCD), on nitrification rate and microbial biomass in a grazed pasture soil. Australian Journal of Soil Research 42: 927-932.

EPAGRI/CIRAM - Empresa de Pesquisa Agropecuária e Extensão Rural de Santa Catarina/Centro de Informações de Recursos Ambientais e de Hidrometereologia. 2013. Monitoramento dos fenômenos climáticos e seus impactos: climatologia de chuvas. Disponível em: http://ciram.epagri. sc.gov.br. Acesso em: 15 jan. 2014.

FATMA. 2014. Instrução Normativa $n^{0} 11$ - suinocultura. Florianópolis: FATMA. Disponível em: http://www.fatma. sc.gov.br/conteudo/instrucoes-normativas. Acesso em: 03 ago. 2016.

FIXEN PE. 2009. Mejores prácticas de manejo para una mayor eficiencia en la nutrición de cultivos. 126p. (Informaciones Agronómicas). 
NICOLOSO RS et al. 2013. Acúmulo de nitrogênio e produtividade do milho adubado com dejetos líquidos de suíno aplicados em superfície ou injetado no solo com ou sem inibidor de nitrificação. In: III Simpósio internacional sobre gerenciamento de resíduos agropecuários e agroindustriais. Anais... Brasília: Embrapa. 24p.

SCHIRMANN J et al. 2013. Inibidor de nitrificação e aplicação parcelada de dejetos de suínos nas culturas do milho e trigo. Revista Brasileira de Ciência do Solo 37: 271-280.

TEDESCO MJ et al. 1995. Análises de solos, plantas e outros materiais. 2.ed. Departamento de Solos da UFRGS. 174p. (Boletim Técnico 5).

VALLEJO A et al. 2005. Comparison of $\mathrm{N}$ losses $\left(\mathrm{NO}_{3}\right.$, $\mathrm{N}_{2} \mathrm{O}$, and $\mathrm{NO}$ ) from surface applied, injected or amended (DCD) pig slurry of an irrigated soil in a Mediterranean climate. Plant and Soil 272: 313-325. 